In conclusion, the authors wish to express their appreciation to those in charge of the Chemical Laboratories at the University of California and the University of Nevada where this work was done, and also to Mr. W. J. Cummings for apparatus.

NEW ORLEANS, Louistana and HoNOLuLo, T. H.

[CONTribution from the DepartMent of Chemistry, Col,umbia University, No. 393]

\title{
INFLUENCE OF AMINO ACID IN PROTECTING AMYLASE FROM INACTIVATION BY MERCURY
}

\author{
By H. C. Sherrman and Mary L. Caidwelil \\ Received August 3, 1922
}

In work which we reported last year ${ }^{1}$ it was found that histidine and tryptophane differed from other amino acids tested in this Laboratory in that they showed no favorable influence upon the amyloclastic action of purified pancreatic amylase. In the oral discussion of the results it was suggested by Dr. Gortner that since precipitation by mercury is used as a step in the preparation of these two amino acids ${ }^{2}$ it is conceivable that their failure to increase the activity of the amylase might be due to the presence of a trace of mercury accidentally remaining as an impurity. If this were true, it should follow that equal or larger amounts of mercury would be similarly destructive in the presence of other amino acids.

Experiments have therefore been carried out in the same manner as previously reported for histidine and tryptophane in which glycine with and without mercuric chloride was added to the starch paste substrate before digestion with the amylase. Mercury was added in the form of chloride because, had any mercury been present in the histidine dihydrochloride used in the tests previously reported, it would have been in the form of chloride, and because no disturbing influence could be introduced by the chloride ion inasmuch as in all our experiments with pancreatic amylase liberal amounts of chloride and phosphate are regularly used in the substrate solution. ${ }^{3}$

The mercuric chloride was used in final concentrations of $0.000006 \mathrm{M}$ and $0.000003 M$ in the digestion mixture, which makes it comparable with results previously published from this laboratory upon the effect of copper sulfate. ${ }^{4}$ These concentrations of mercury, although numerically small, are much larger than could have been introduced as accidental impurity

${ }^{1}$ Sherman and Caldwell, This Journal, 43, 2469 (1921).

"Hopkins and Cole, J. Physiol, 27, 418 (1901). Kossel and Kutcher, Z. physiol. Chem., 31, 165 (1900-1901). Osborne, Leavenworth and Brautlecht, Am. J. Physiol., 23, 180 (1908). Plimmer, "Chemical Constitution of the Proteins," Longmans, Green and Co., I, pp. 27, 56, 1917.

${ }^{3}$ Sherman and Kendall, This Journal, 32, 1087 (1910) and subsequent papers from this Laboratory.

${ }^{4}$ Ibid., 43, 2454, 2461 (1921). 
in the analyzed preparations of histidine and tryptophane used in the experiments referred to above, for the mercury used as precipitant in the preparation of these amino acids is subsequently removed by sulfide precipitation, followed by the other steps of the methods for the purification of histidine and tryptophane, ${ }^{2}$ so completely that no trace is revealed by analysis of the purified amino acids and of these only one part is used per thousand parts of the digestion mixture.

The mercuric chloride used in the experiments described below was an analyzed salt further purified by repeated recrystallization. As in our previous work, the hydrogen-ion concentration of the digestion mixtures was carefully determined and so controlled as to keep it at the optimum for the enzyme used (pancreatic amylase), namely, $\mathrm{C}_{\mathrm{H}^{+}}=10^{-6.93}$ in all cases. ${ }^{5}$

Three series of experiments were carried out.

First Series. Influence of Mercuric Chloride and Glycine upon the Amyloclastic Action of Purified Pancreatic Amylase

The experiments were performed in the manner described in our previous paper. ${ }^{1}$ For the sake of brevity only the end results will here be given.

The amount of enzyme preparation which, without the addition of mercury or glycine, brought about the splitting of the standard amount of starch in the standard time was $0.0075 \mathrm{mg}$.

In the presence of $0.000003 \mathrm{M}$ mercuric chloride, $0.0083 \mathrm{mg}$. was required, showing inactivation to the extent of about $10 \%$. The addition of $50 \mathrm{mg}$. of glycine per $100 \mathrm{cc}$. of the solution containing mercuric chloride completely protected the amylase and resulted in greater activity than when neither the mercury nor the amino acid was present; for in the presence of both the mercury and the glycine the amount of enzyme preparation required was in one experiment 0.007 , and in another $0.0073 \mathrm{mg}$.

Second Series. Influence of Mercuric Chloride and Glycine upon the Saccharogenic Action of Purified Pancreatic Amylase

Having shown the protective effect of glycine in experiments upon the amyloclastic action of the enzyme, several experiments were made to determine whether the same effect would be obtained in tests of its saccharogenic activity. Some results of typical experiments are shown in Table I.

It is seen that small concentrations of mercuric chloride, 0.000003 and $0.000006 M$, have a decided inactivating effect and that small amounts of glycine, 50 to $100 \mathrm{mg}$. per $100 \mathrm{cc}$, protect the amylase against this inactivation of its saccharogenic power.

- This Journal, 41, 231 (1919). 
TABLE I

Effect of Glycine in Protecting the Saccharogenic Activity of Purified PanCREATIC AMYLaSE From Inactivation by MERCuRIC ChLoRIDE

Additions to digestion mixture

Glycine per $100 \mathrm{cc}$.

$\mathrm{Mg}$.

None

None

None

50

100

50

100

50
$\mathrm{HgCl}_{2}$ conc. $M$

None

0.000003

0.000006

None

None

0.000003

0.000003

0.000006
Cuprous oxide obtained

Mg.

194

139

112

240

236

217

214

208

\section{Third Series. A Comparison of Glycine and Phenylalanine}

In order to preclude the possibility of the protective effects above noted being specific to glycine, another series of experiments was performed in which glycine and phenylalanine were tested side by side. Typical results are shown in Table II.

TABLE II

A Comparisón of the Protective Action of Glycine and Phenylalanine Against Injury by Mercuric Chloride to the Saccharogenic Activity of Pancreatic AMYLASE

Additions to digestion mixture Amino acid

$\begin{array}{lr} & \mathrm{Mg} . \\ \text { None } & \\ \text { None } & \\ \text { Glycine } & 50 \\ \text { Phenylalanine } & 50 \\ \text { Phenylalanine } & 100 \\ \text { Phenylalanine } & 100 \\ \text { Phenylalanine } & 50 \\ \text { Glycine } & 50\end{array}$

$\begin{array}{cc}\text { Mercuric chloride } & \begin{array}{c}\text { Cuprous oxide } \\ \text { obtained } \\ M .\end{array} \\ \text { Mg. } \\ \text { None } & 194 \\ 0.000003 & 139 \\ 0.000003 & 226 \\ 0.000003 & 230 \\ 0.000003 & 228 \\ \text { None } & 253 \\ \text { None } & 254 \\ \text { None } & 258\end{array}$

These results show that phenylalanine exerts the same protective effect as glycine and that under the conditions of these experiments $50 \mathrm{mg}$. or $100 \mathrm{mg}$. has about equal effect in either case.

\section{Summary and Conclusion}

The above results show that glycine and phenylalanine and, therefore, presumably other amino acids, protect against small concentrations of mercuric chloride added when testing the activity of purified pancreatic amylase, and allow the latter to act almost as efficiently as if no mercury were present.

Since there is a decided increase in the activity of the amylase in the presence of the amino acids even when mercuric chloride has been added, it seems certain that such minute amounts of mercury as might conceivably 
have been present in the histidine and tryptophane preparations used could not account for their entire lack of activating influence upon the amyloclastic action of the enzyme.

We are greatly indebted to the Carnegie Institution of Washington for grants in aid of this investigation.

NEW YORK, N. Y.

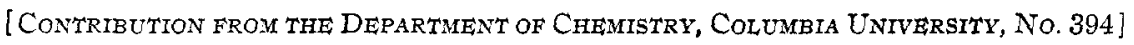

\section{INFLUENCE OF LYSINE UPON THE HYDROLYSIS OF STARCH BY PURIFIED PANCREATIC AMYLASE}

By H. C. Sherman and Mary L. Caldweli

Received August 3, 1922

The studies of the influence of certain natural amino acids on the hydrolysis of starch by pancreatic amylase already reported from this Laboratory ${ }^{1}$ have been extended to lysine with results which throw interesting light upon the nature of the enzyme.

The experimental methods were essentially the same as those used in the work with other amino acids and the precautions regarding the selection and care of glass ware, the purification of the water and other materials, the exclusion of light, and the standard conditions of temperature, activating salts, ${ }^{2}$ and hydrogen-ion concentration ${ }^{3}$ repeatedly emphasized in reports from this Laboratory were carefully observed.

The lysine hydrochloride used was prepared from lysine picrate by the method described by Kossel. ${ }^{4}$ The picrate was dissolved in an aqueous solution of hydrochloric acid and the picric acid removed by extracting with ether. This was repeated several times after the ether extract upon evaporation gave no color, taste, or weighable residue. The lysine hydrochloride was obtained by evaporating the solution with excess of hydrochloric acid and recrystallizing several times from absolute alcohol. The product obtained was white, crystalline, hygroscopic, and had the melting point of the dihydrochloride $\left(192-193^{\circ}\right)$. Purified pancreatic amylase No. $24 \mathrm{~B}$ prepared as previously described ${ }^{6}$ was used.

Lysine was tested for its influence upon both the amyloclastic and the saccharogenic activities of the amylase by the methods previously described. ${ }^{1}$ The calculated weight of lysine dihydrochloride needed to give the desired amount of lysine was added directly to the fully activated starch paste in the cylinder before making it up to volume and enough

${ }^{1}$ Sherman and Walker, THrs JournaL, 41, 1866 (1919); 43, 2461 (1921). Sherman and Caldwell, ibid., 43, 2469 (1921).

2 Sherman and Kendall, ibid., 32, 1073 (1910), and subsequent papers from this Laboratory.

${ }^{3}$ Sherman, Thomas and Baldwin, ibid., 41, 231 (1919).

4 Kossel, Z. physiol. Chem., 26, 586 (1898-9).

s Abderhalden's "Biochemisches Handlexikon," Julius Springer, vol. IV, 645 (1911).

- Sherman and Neun, This Journal, 41, 1854 (1919). 